\section{Perspectivas do crescimento das populações indígenas e os direitos constitucionais*}

\author{
Maria Stella Ferreira Levy**
}

\section{Introdução}

O Estado Liberal e, subseqüentemente, o Estado Social caracterizaram-se por uma centralização de poder que faz parte do projeto autoritário de governo de Estado, em geral ineficiente enquanto controle. As grandes modificações ocorridas na sociedade mundial, especialmente na década de 80, vêm desaguando no Estado Social de Direito, também dito Democracia Dialógica, cujo caminho vai na direção de uma descentralização, que tende a privilegiar o diálogo entre os grupos existentes na sociedade, fortalecendo o poder local em detrimento do central.

Ao que parece, esse objetivo deveria ser mais fácil de se concretizar em países economicamente mais ricos, com territórios e populações menores (em relação aos do Terceiro Mundo), como são os da Europa; mas os conflitos minoritários quanto a língua, história, religião e interesses políticos e econômicos, que pululam em todos os seus rincões, fazem-nos duvidar dessa afirmação. No mundo economicamente subdesenvolvido, leia-se mais pobre, onde os territórios e populações são bem maiores e mais espalhadas, e diante da variedade geoambiental e da diversidade física, econômica, cultural, etc. de seus habitantes, fica bem mais distante a implementação dessa proposta.

Essas mudanças de valores exigem uma sociedade civil organizada, em que a "educação coletiva" para resolução de problemas e conflitos sociais depende da comunicação, divulgação e ação dos vários setores da sociedade e de cada um de nós. As idéias de como construir uma sociedade dialógica tem que ser compartilhada pelos componentes da sociedade e, nesse contexto, o poder local assume as rédeas do processo.

Esse novo modelo internacional teve repercussões no Brasil e em várias de suas instituições. A Funai, por exemplo, não ficou de fora, embora a compreensão desse novo modelo ainda dependa muito da postura de seus dirigentes. A filosofia do Serviço de Proteção ao Índio - SPI, ao ser criado, era etnocêntrica (PASSUELO, 1993, p. 17), visando integrar os índios na cultura nacional por meio de sua pacificação e possivelmente pela miscigenação, o que em parte também estava presente na concepção de Clóvis Bevilácqua (1921, p. 185), no seu projeto do Código Civil entregue em fins do século XIX, depois modificado no Senado da República quando o senador Muniz Freire restringiu a capacidade civil dos índios em continuidade da dita tutela orfanológica dos séculos anteriores. ${ }^{1}$ Essa pacificação não reduziu os conflitos existentes, e sim favoreceu a extinção de novos grupos tribais e também estendeu e ampliou a quantidade de atrocidades que já eram cometidas desde 1500.

A Funai substituiu o SPI, em 1967, e não só continuou com a filosofia e prática anterior de pacificação e suas conseqüências, como também incorporou uma concepção desenvolvimentista com uma tecnologia mais contundente, que mais estragos causou, construindo "um gigantesco complexo rodoviário na Amazônia” e em outros locais,

\footnotetext{
* Trabalho apresentado no XIV Encontro Nacional de Estudos Populacionais, Abep, realizado em Caxambu - MG - Brasil, de 20 a 24 de setembro de 2004.

** Graduada em Direito pela PUC/SP e doutora em Direito Civil, Faculdade de Direito/UFMG. Professora associada do Departamento de Epidemiologia, Faculdade de Saúde Pública/USP.

1 O Decreto no 5.484 de julho de 1928 dividia os grupos indígenas em quatro categorias, a depender do critério de grau de aculturação e tipo de aldeamento, considerando nulos os atos praticados entre os civilizados e índios de três dessas categorias, excluindo a quarta referente ao indígena que vive misturado com outros segmentos da cultura nacional. A este se aplicaria o Direito comum emancipando-os da tutela orfanológica.
} 
além das hidrelétricas, que cortavam e alagavam, respectivamente, as terras habitadas pelos índios.

Com a promulgação da Constituição Cidadã em 1988, conforme seus artigos 231 e parágrafos e 232, do capítulo VIII Dos Índios, essa postura integracionista deu lugar ao dever do Estado de pensar e tratar as populações indígenas de maneira diferenciada, reconhecendo aos índios, entre outros, o direito de manter sua organização social, tradições, os direitos sobre as terras que ocupam tradicionalmente e, principal, os considerando partes legítimas para ingressar em juízo em defesa de seus direitos e interesses, como qualquer outro cidadão brasileiro.

Em face das mudanças ocorridas nas relações com as nações indígenas - acontecimentos para os quais foram importantes a forte pressão de antropólogos, juristas, cientistas políticos, missões religiosas e ONGs, a preocupação do governo com a imagem do país e sua repercussão internacional, os tratados de direitos de minorias e direitos humanos dos quais somos signatários desde $1966^{2}$ e a não menos importante atuação da liderança indígena -, foi possível refrear alguns abusos junto aos poderes do Estado, principalmente quanto a invasões de terras. Essas alterações em nível da filosofia de como encarar as diferenças fez com que as relações jurídicas fossem estabelecidas em novas bases, tornando possível a preparação e educação formal de alguns índios, que se estruturaram e organizaram seus povos para se defender no que se refere aos poderes constituídos, evidenciando amadurecimento político, desenvolvendo uma postura que privilegia o direito constitucional e, ao que parece, estimulando o desejo de grande parte desses grupos de crescer demograficamente.

Os povos indígenas, na conquista de seus direitos, vêm, a duras penas, trilhando um caminho em direção a uma democracia partilhada, dialógica. Assim, em 1972 estru- turou-se o Conselho Indigenista Missionário (Cimi), órgão da Conferência Nacional dos Bispos do Brasil (CNBB), cuja finalidade era dar assessoria aos missionários que atuavam nas comunidades indígenas, e que tentou, sem sucesso, chegar a um consenso de interesses com a Funai. ${ }^{3}$

Em 1974, o Cimi promoveu o Primeiro Encontro de Chefes Indígenas para que líderes e representantes dos vários grupos pudessem se conhecer e discutir seus problemas comuns. Por alguma razão, a nova diretoria da Funai, em 1977, proibiu os missionários do Cimi de entrarem nas áreas indígenas. Contudo, outros grupos de apoio à causa começaram a surgir e se converteram em canais eficazes de denúncia e pressão, utilizando-se de fóruns e publicações de âmbito nacional.

Formaram-se, assim, a Associação Nacional de Apoio ao Índio (Anai), com sede em Porto Alegre e subsedes em outros estados, e a Comissão Pró-Índio de São Paulo (CPI-SP), que apóia a União das Nações Indígenas (UNI) fundada em 1980, promovendo encontros e assembléias de lideranças indígenas e cujo departamento jurídico se empenha em elaborar uma legislação indigenista com a participação dessas lideranças, prestando também assessoria aos diferentes grupos. Ainda em São Paulo funciona o Centro de Trabalho Indigenista (CTI), que desenvolve projetos para áreas específicas e o Instituto Socioambiental (ISA), que substituiu o Núcleo de Direito Indígena (NDI), ampliado para outras finalidades. Em Cuiabá, focalizando a questão indígena e dos camponeses, localiza-se o Centro de Documentação Terra e Índio (CDTI), afora outras organizações em outras regiões.

De 1974 a 1980, foram realizadas 13 assembléias de chefes indígenas de várias áreas do país, e se logrou publicar um boletim em nível nacional e o jornal Porantin, alertando sobre as repetidas violações dos direitos indígenas. Em 1980 foi estruturada

\footnotetext{
2 Ver, para esses diplomas, Maia (1993) e comentários em Papadópoli (1995).

3 Este e os próximos cinco parágrafos que seguem, bem como as informações e dados mencionados, resumem as páginas 266 a 269 do artigo de Junqueira e Paiva (1988).
} 
a Sociedade Brasileira de Indigenistas, que se propunha a dialogar com a Funai, uma vez que seus funcionários encerrados em Brasília, no mais das vezes sem conhecer as necessidades e interesses de seus representados, planejavam e tomavam decisões contrárias às comunidades dos índios, sem a preocupação de se informar a respeito de determinados indivíduos, que, cooptados, agiam em interesse próprio e contrariamente aos interesses maiores do seu grupo.

A Funai não reconheceu a Sociedade e nem a UNI (União das Nações Indígenas), declarando-se a única legítima representante dos índios. Essa declaração fundamentava-se em determinação do presidente da República, que, baseado no relatório do SNI, declarava não ser prudente que os grupos indígenas se agrupassem em um só organismo.

Em 1981 reuniram-se, em São Paulo, 73 líderes e 32 entidades de apoio, com o fim de preparar o Primeiro Encontro Nacional de Povos Indígenas, realizado em junho de 1982, com a presença de 228 líderes que representavam 48 nações. No segundo encontro, organizado por Mario Juruna e a UNI, em abril de 1984, compareceram 450 líderes tribais de mais de 50 povos indígenas. Nessas reuniões, as propostas e reivindicações concentraram-se no direito do índio de ir e vir, liberdade de reunião, direito de se organizarem, que não fossem declarados "não-índios" contra sua vontade, demarcação de suas terras e concessão de títulos de propriedade.

Vale ressaltar o papel do chefe da aldeia Xavante, Mário Juruna. "Em 1980 foi o chefe da aldeia Xavante Namunkurá, Mario Juruna, que havia se convertido no representante mais importante da luta indígena no Brasil, eleito presidente de Comissão do 4ㅇ․ Tribunal Bertrand Russel de Direitos Humanos" (JUNQUEIRA; PAIVA, 1988, p. 269). Segundo Carlos Marés de Souza Filho (1993, p. 309), Juruna recebeu convite para viajar ao exterior, com a finalidade de "apresentar a situação do indígena brasileiro a entidades de defesa dos direitos humanos. Valendo-se da tutela imposta pelo Estatuto do Índio, o Ministro do Interior, chefe hierárquico do Presidente da FUNAI, proibiu sua saída do país".
Conforme relata Rafael José de Menezes Bastos (1982, p. 59-60), que teve em mãos os autos desse processo:

Posta a disputa ao nível judiciário, o caso Mário Juruna se conforma basicamente pela impetração, no Tribunal Federal de Recursos, dos Habeas Corpus sob no 4.876 (de 13 de novembro de 1980) e 4.880 (do seguinte dia 17), em favor da liberdade do Chefe Xavante de ir e vir, podendo, assim, comparecer ao IV Tribunal Bertrand Russel. Note-se que a FUNAI e o Ministério do Interior publicamente - através de jornais, revistas, etc. - não concederam autorização ao Sr. Juruna para isto poder concretizar, o que se evidenciou, praticamente, pela também negativa da Polícia Federal de a ele conceder passaporte. Impetrados, o primeiro pelo Sr. Jorge de Oliveira Beja, o segundo, por José Oliveira Costa e Antonio Modesto da Silveira, foram os dois apensados numa somente questão, tendo como relator o Ministro Adhemar Raymundo.

Conclui o autor: "a causa tendo sido ganha pelo Sr. Juruna, exatamente em função da inspiração que os ministros do Tribunal Federal de Recursos foram buscar na Declaração Universal dos Direitos do Homem". Diz ainda: "Sobretudo levei em conta os votos acórdãos - (preliminar e mérito) do Relator, os respectivos acórdãos, bem como as petições iniciais e justificativas do Ministro do Interior, além de outros votos especialmente notáveis como, entre outros, o do Ministro Washington Bolívar de Brito."

Foi através de recurso que, citando Eduardo Viveiros de Castro (1982, p. 31), "O TRF considerou que a condição de tutelado de Juruna não legitimava a proibição de viajar (...) um caso límpido de abuso do poder". Mesmo assim, "o habeas corpus obteve quinze votos a favor e nove contra, com o que pôde sair para a Holanda onde assistiu a parte final dos trabalhos do 4 ㅇ. Tribunal" (JUNQUEIRA; PAIVA, 1988, p.267).

Em 1981, Juruna foi eleito deputado federal pelo Rio de Janeiro, com 31.805 votos, e teve seu projeto de lei, no 661 $A D-83$, que previa uma reestruturação da Funai com a participação dos índios, aprovado em plenária do Congresso em 1983, evidenciando uma "nova consciência étnico-política voltada contra a dominação 
colonial de que o índio foi objeto", conforme se expressa João Pacheco de Oliveira (1985, p.26). De imediato, antes de ser submetido ao Senado, surgiram dois projetos com interesses contrários à emancipação e demarcação de terras indígenas.

A visibilidade e o esforço de Juruna e demais líderes e ativistas de outras tribos não foram em vão. A regularização da situação fundiária das terras indígenas no Brasil, que, segundo o Estatuto do Índio de 1973, deveria ser feita no prazo de cinco anos a partir de sua publicação, não ocorreu até os dias de hoje, embora de 1996 a 2000 muito tenha sido feito a respeito dessa matéria, mas mais da metade ainda está por fazer. Essa é uma das questões diretamente ligadas ao crescimento demográfico de vários desses povos, uma vez que o território é a base de sua cultura e de sustentação econômica tanto interna quanto externa.

A experiência de lutas e preconceitos de mais de 500 anos e a organização política que vem sendo conquistada pelos índios, a partir dos anos 70 , tornaram possível que a lei indígena fosse elevada ao patamar constitucional. Todo esse processo e a abertura política e jurídica propiciada pela Constituição Federal de 1988 possibilitaram a criação de associações indígenas registradas na forma de sociedades civis, como por exemplo nos seis estados da Amazônia (AM, $\mathrm{RO}, \mathrm{RR}, \mathrm{AC}, \mathrm{PA}, \mathrm{AP}$ ), onde em uma década passaram de dez para 180 e são estimadas em mais de 250 , se for considerado o território compreendido pela Amazônia legal, que inclui Mato Grosso, Tocantins e parte do Maranhão.

Algumas das organizações indígenas ou a elas ligadas se valem de recursos externos, no geral dirigidos para projetos de saúde, educação, auto-sustentação, gestão territorial, etc., com colaboração de ONGs ambientais e sociais, preocupadas também com os efeitos possíveis da globalização nas questões do meio ambiente. Mas em nível nacional, o fator mais importante foi a
"Constituição Federal de 1988 que possibilitou às associações se constituírem em pessoas jurídicas (...) [e ainda] o processo de retração do Estado da gestão direta da 'questão indígena' e o esvaziamento político orçamentário da FUNAI, criada há três décadas pelo regime militar no quadro de suas políticas de desenvolvimento da Amazônia". ${ }^{4}$

Segundo Carmen Junqueira (2000, p. 28), atualmente,

as associações são o núcleo de interlocução com o Estado, com as agências financiadoras ou com qualquer outra entidade. Tradicionalmente para entrar em uma aldeia indígena era preciso pedir autorização ao Ministério da Justiça, à Funai. Hoje as entidades do governo é que solicitam autorização. Quem decide se convém à comunidade a entrada é a associação. As associações geram os negócios modernos da comunidade.

Hoje não só há um maior número de associações, como também aumentou o número de "confederações". Entre outras: a Associação Terras Indígenas do Xingu (Atix) dos 17 povos que habitam a região do Xingu; no Rio Negro, a Federação das Organizações Indígenas do Rio Negro (FOIRN) criada em 1986, que inclui pelo menos 16 etnias pertencentes a três grandes famílias lingüísticas (AZEVEDO, 1994, p. 236); ${ }^{5}$ e a Coordenação das Organizações Indígenas da Amazônia Brasileira (Coiab).

Aryon Rodrigues (apud FRANCHETTO, 2001) estima que, às vésperas da conquista, eram faladas no Brasil 1.273 línguas, das quais se perderam $85 \%$, sendo hoje cerca de 180, a maioria concentrada na Amazônia e em média com menos de 200 falantes por língua, embora haja grupos, como os Guarani, os Tikuna, os Terena, os Macuxi e os Kaingang, com 10.000 a 20.000 falantes.

\section{Estimativas recentes}

Não foi apenas o número de sociedades de direito civil que cresceu - e neste

\footnotetext{
4 Os dados desse parágrafo e do anterior provêm do artigo de Albert (2001).

${ }^{5}$ No artigo estão citados todos os grupos e suas denominações, além de dados do Censo Indígena Autônomo do Alto Rio Negro, 1992.
} 
artigo são consideradas apenas aquelas da Amazônia -, mas também o número de índios e, em alguns lugares, o de aldeias, como no caso de grupos de Xavante do Mato Grosso (PENNA, 1984). ${ }^{6}$ Há inúmeros outros exemplos na literatura sobre o crescimento populacional de povos indígenas, referentes a grupos específicos, ${ }^{7}$ contudo, devido aos problemas de contagem e coleta e particularmente ao que os antropólogos denominam de categoria do "índio genérico", dificilmente são encontrados números consolidados para o total do Brasil.

Outras estimativas, feitas pela Funai/ Cimi/Igreja católica (ISA, 2001), indicam que os 216 povos indígenas contemporâneos têm crescido a partir do final da década de 70 , contando com 350 a 500 mil pessoas, embora alguns povos tenham perdido população e outros estejam ameaçados de extinção (há 12 povos com população entre 2 e 28 indivíduos). Desses 216 povos, 40 $(18,5 \%)$ têm parte de sua população residindo em outros países e, mesmo quando há informações demográficas a respeito, essas parcelas não foram consideradas nem na estimativa global para o Brasil, nem para a classificação apresentada Quadro 1.

As estimativas numéricas da população indígena vêm apresentando enormes variações desde o descobrimento do Brasil. Segundo o Anuário Estatístico Brasileiro de 1991, que traz um capítulo especial sobre áreas indígenas do Brasil, índios eram apenas os que habitavam os postos indígenas da Funai ou as missões religiosas (AZEVEDO, 1994, p. 240).

A população indígena brasileira no século XVI variava em torno de 2 a 4 milhões, ${ }^{8}$ e foi, a partir do século $X X$, estimada retoricamente por uma espécie de densidade populacional média, com base no tamanho teórico de comunidades; depois baseou-se numa relação entre tipo de organização e recursos naturais para sua subsistência; posteriormente, foram construídas médias harmônicas aproximadas, a partir de grupos considerados "homogêneos" em diferentes habitats e expandidas para todo o território nacional. Mais tarde dados demográficos de algumas tribos foram utilizados para esses cálculos, mas até o final da década

\section{QUADRO 1}

Estimativas do número de pessoas, segundo o número de grupos indígenas

Brasil - 2000

61 povos $(28,2 \%)$ têm até 200 indivíduos

50 povos $(23,1 \%)$ têm entre 201 e 500 indivíduos

37 povos (17,1\%) têm entre 501 e 1.000 indivíduos

43 povos (19,9\%) têm entre 1.001 e 5.000 indivíduos

09 povos (4,1\%) têm entre 5.001 e 10.000 indivíduos

05 povos (2,3\%) têm entre 10.001 e 20.000 indivíduos

01 povo tem entre 20.001 e 30.000 indivíduos

02 povos têm mais de 30.000 indivíduos

Mais 42 povos indígenas isolados

Fonte: Instituto Socioambiental (2001, p. 15). Contagem feita pela Funai/Cimi/Igreja católica.

\footnotetext{
${ }^{6} \mathrm{O}$ autor chama a atenção para esse fato ter ocorrido após a retomada das terras pelos índios e ao mesmo tempo faz uma crítica à maneira como o órgão tutor agiu nesse episódio.

7 Vide, entre outros, Pagliaro (2002), Azevedo e Fonseca (1998) e Penna (1984).

8 Ver um ótimo retrospecto sobre números de índios e das bases desses cálculos, quando existiram, no artigo de Ribeiro (1983).
} 
de 40 os indicadores têm mostrado crescimento negativo, sem contar a extinção de uma centena de tribos desde o início da colonização. De alguns anos para cá, antropólogos têm notado crescimento do número de índios nas tribos com as quais convivem.

Uma estimativa do número de índios para os últimos 20 anos encontra-se no Quadro 2. Observa-se a grande discrepância quando comparados os dados censitários e os provenientes do Cimi.

O Mapa 1 apresenta a distribuição da população indígena em 1980, segundo alguns estados e regiões do Brasil.

Dados para o período de 1996 a 2000 indicam que a maioria das etnias indígenas tem crescido $3,5 \%$ ao ano, valor maior do que a média de $1,6 \%$ estimada pelo IBGE para a população brasileira, no mesmo período (FOLHA DE S. PAULO, 24/03/2001).

O censo de 1991 mostra uma pirâmide etária rejuvenescida, cujos resultados estão mais ou menos próximos aos de outras fontes indigenistas (apud AZEVEDO; FONSECA, 1998, p. 18). A Tabela 1 apresenta dados dos censos de 1991 e 2000, da população total e indígena, para os estados brasileiros e o crescimento geométrico entre os dois últimos censos.

A análise da Tabela 1 revela situações interessantes, apesar de todas as limitações e dificuldades em coletar dados relativos a índios, particularmente para aqueles residentes em áreas urbanas, sobre o que inúmeros pesquisadores vêm chamando a atenção.
Mesmo hoje, as dificuldades para calcular números de índios no país são enormes e qualquer cálculo de crescimento precisa ser visto restritivamente. Maria Marta Azevedo (1994, p. 235), por exemplo, afirma que as sociedades indígenas deveriam ser recenseadas como etnias. A partir daí seria possível contar o número de pessoas/índios integrantes do grupo. Contudo, a migração de índios para cidades $-e$ a autora se refere a grupos do Alto Rio Negro que se deslocaram para o município de São Gabriel da Cachoeira e mesmo Manaus - oferece um problema de difícil solução metodológica, que ainda estamos longe de resolver adequadamente.

Vale lembrar que o censo realizado em 1991 deveria ter sido feito em 1990, mas não o foi pelo fato de o país estar enfrentado problemas políticos sérios. Finalmente foi liberada a verba para sua realização, porém bastante restringida, o que ocasionou inúmeros problemas, como a revolta dos recenseadores que não receberam seus pagamentos, o que tornou esse censo muito problemático quanto à sua cobertura.

Nos censos anteriores ao de 1991, era coletada a cor das pessoas, sendo que os índios eram classificados de pardos, o que ficava a cargo dos preconceitos e da impossibilidade de enquadramento nas respostas existentes nos questionários do censo. Após anos de reivindicações e debates, os dois últimos censos apresentaram uma categoria "índios" nessa mesma variável, embora ainda haja muitos problemas a serem solucionados, para uma adequada comparação entre os levantamentos. Já o censo de 2000

\section{QUADRO 2}

Algumas estimativas sobre a população indígena

Brasil - 1980-2000

\begin{tabular}{|lll|}
\hline Anos & Total & Fonte dos dados \\
1980 & $227.801(1)$ & Porantin, out./1980, Egydio Schwade. \\
1991 & 294.135 & Censo IBGE - Porantin, out./1989, p. 8 \\
1996 & 325.652 & Documento da Presidência da República: "Sociedades Indígenas e a Ação do Governo" \\
2000 & 550.438 & Porantin, encarte, março/2000 \\
2000 & 701.462 & IBGE, Censo de 2000 (publicado em 2002) \\
\hline
\end{tabular}

Fonte: Sedoc, Secretaria do Cimi Nacional.

(1) Desses, 15.000 arredios e 30.000 desaldeados. 
MAPA 1

Distribuição da população indígena

1980

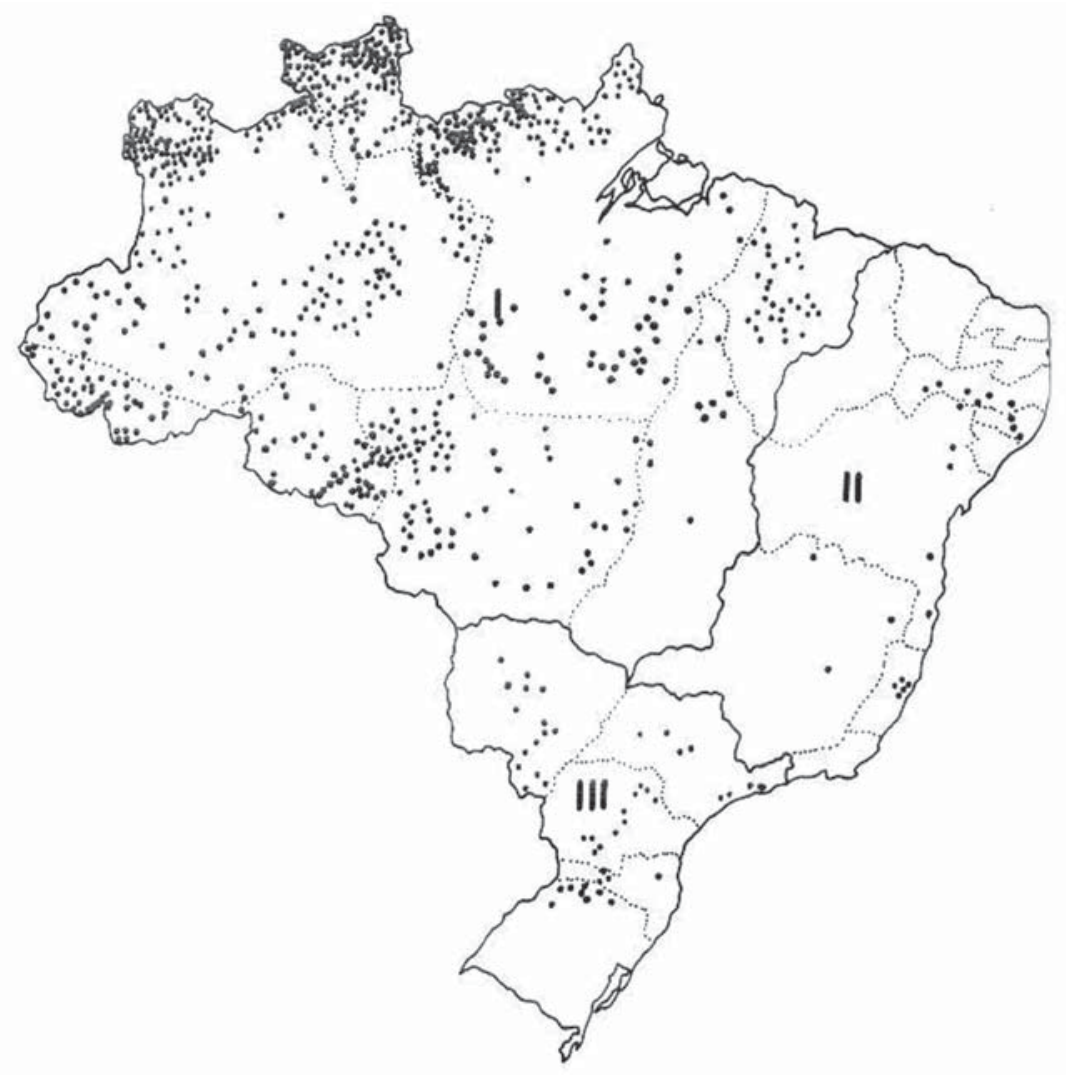

\begin{tabular}{lc} 
Estados e regiões & População \\
\hline Acre/Rondônia & 10.490 \\
Roraima/Amazonas (parte do Estado) & 72.026 \\
Pará/Amapá & 10.716 \\
Maranhão/Norte de Goiás & 9.578 \\
Mato Grosso (Norte e Sul) & 33.681 \\
Leste/Nordeste & 32.554 \\
Sul & 14.405 \\
Total & 182.801 \\
\hline Grupos arredios & 15.000 \\
Destribalizados & $30.000(1)$ \\
Total geral & 227.881 \\
\hline
\end{tabular}

Fonte: Dados apresentados pelo padre Egídio Shwade. Atualizados em 1980.

(1) Segundo pesquisa da Universidade do Amazonas (1976) são estimados, em Manaus, 10.000 índios destribalizados. 
TABELA 1

População indígena e total, participação da população indígena sobre o total e crescimento geométrico, segundo Unidades da Federação

Brasil - 1991-2000

\begin{tabular}{|c|c|c|c|c|c|c|c|c|}
\hline \multirow[t]{2}{*}{$\begin{array}{l}\text { Unidades da } \\
\text { Federação }\end{array}$} & \multicolumn{2}{|c|}{ População - 2000} & \multicolumn{2}{|c|}{ População - 1991} & \multicolumn{2}{|c|}{$\begin{array}{c}\text { Participação } \\
\text { da população } \\
\text { indígena sobre } \\
\text { a total (\%) } \\
\end{array}$} & \multicolumn{2}{|c|}{$\begin{array}{c}\text { Crescimento } \\
\text { geométrico } \\
1991 \text { a } 2000(\%)\end{array}$} \\
\hline & Indígena & Total & Indígena & Total & 2000 & 1991 & $\begin{array}{l}\text { População } \\
\text { indígena }\end{array}$ & $\begin{array}{c}\text { População } \\
\text { total }\end{array}$ \\
\hline Rondônia & 10.683 & 1.380 .952 & 4.138 & 1.133 .262 & 0,77 & 0,37 & 11,11 & 2,22 \\
\hline Acre & 8.009 & 557.882 & 4.746 & 417.091 & 1,44 & 1,14 & 5,99 & 3,28 \\
\hline Amazonas & 113.391 & 2.817 .252 & 67.879 & 2.102 .774 & 4,02 & 3,23 & 5,87 & 3,30 \\
\hline Roraima & 28.128 & 324.397 & 23.423 & 217.581 & 8,67 & 10,77 & 2,05 & 4,54 \\
\hline Pará & 37.681 & 6.195 .965 & 16.134 & 4.949 .210 & 0,61 & 0,33 & 9,88 & 2,53 \\
\hline Amapá & 4.972 & 477.032 & 3.248 & 289.046 & 1,04 & 1,12 & 4,84 & 5,72 \\
\hline Tocantins & 10.581 & 1.157 .690 & 5.049 & 918.394 & 0,91 & 0,55 & 8,57 & 2,61 \\
\hline Maranhão & 27.571 & 5.657 .552 & 15.673 & 4.929 .682 & 0,49 & 0,32 & 6,48 & 1,54 \\
\hline Piauí & 2.664 & 2.843 .428 & 317 & 2.582 .076 & 0,09 & 0,01 & 26,68 & 1,08 \\
\hline Ceará & 12.198 & 7.431 .597 & 2.692 & 6.366 .113 & 0,16 & 0,04 & 18,28 & 1,73 \\
\hline Rio Grande do Norte & 3.168 & 2.777 .509 & 394 & 2.415 .083 & 0,11 & 0,02 & 26,06 & 1,57 \\
\hline Paraíba & 10.088 & 3.444 .794 & 3.784 & 3.201 .327 & 0,29 & 0,12 & 11,51 & 0,82 \\
\hline Pernambuco & 34.669 & 7.929 .154 & 10.578 & 7.127 .994 & 0,44 & 0,15 & 14,10 & 1,19 \\
\hline Alagoas & 9.074 & 2.827 .856 & 5.687 & 2.512 .671 & 0,32 & 0,23 & 5,33 & 1,32 \\
\hline Sergipe & 6.717 & 1.784 .829 & 706 & 1.491 .874 & 0,38 & 0,05 & 28,44 & 2,01 \\
\hline Bahia & 64.240 & 13.085 .769 & 16.030 & 11.867 .337 & 0,49 & 0,14 & 16,68 & 1,09 \\
\hline Minas Gerais & 48.720 & 17.905 .134 & 6.112 & 15.743 .534 & 0,27 & 0,04 & 25,94 & 1,44 \\
\hline Espírito Santo & 12.746 & 3.097 .498 & 2.348 & 2.600 .610 & 0,41 & 0,09 & 20,68 & 1,96 \\
\hline Rio de Janeiro & 35.934 & 14.392 .106 & 8.957 & 12.807 .197 & 0,25 & 0,07 & 16,69 & 1,30 \\
\hline São Paulo & 63.789 & 37.035 .456 & 13.166 & 31.588 .816 & 0,17 & 0,04 & 19,16 & 1,78 \\
\hline Paraná & 31.488 & 9.564 .643 & 10.972 & 8.448 .617 & 0,33 & 0,13 & 12,43 & 1,39 \\
\hline Santa Catarina & 14.542 & 5.357 .864 & 4.883 & 4.542 .029 & 0,27 & 0,11 & 12,89 & 1,85 \\
\hline Rio Grande do Sul & 38.718 & 10.187 .842 & 14.477 & 9.138 .475 & 0,38 & 0,16 & 11,55 & 1,22 \\
\hline Mato Grosso do Sul & 53.900 & 2.078 .070 & 32.759 & 1.780 .378 & 2,59 & 1,84 & 5,69 & 1,73 \\
\hline Mato Grosso & 29.126 & 2.505 .245 & 16.548 & 2.026 .070 & 1,16 & 0,82 & 6,48 & 2,39 \\
\hline Goiás & 14.110 & 5.004 .197 & 2.089 & 4.017 .519 & 0,28 & 0,05 & 23,64 & 2,47 \\
\hline Distrito Federal & 7154 & 2.051 .146 & 1.346 & 1.601 .097 & 0,35 & 0,08 & 20,40 & 2,79 \\
\hline Brasil & 734.127 & 169.872 .856 & 294.135 & 146.815 .796 & 0,43 & 0,20 & 10,70 & 1,63 \\
\hline
\end{tabular}

Fonte: IBGE. Censos Demográficos 1991 e 2000.

Nota: As categorias em ambos os censos quanto a raça e cor foram: branca, preta, amarela, parda, indígena e sem declaração.

utilizou o formato de autoclassificação dos próprios recenseados. Esse é um alerta quanto aos dados da Tabela 1, sobre populações indígena e total e o crescimento geométrico.
Chama a atenção, na Tabela 1, o fato de que, em 1991, em apenas cinco estados (AC, AM, RR, AP e MS) a participação da população indígena superava $1 \%$, ampliando para seis, em 2000, com a inclusão de Mato 
Grosso. A maior proporção encontrava-se em Roraima, mas essa porcentagem diminuiu de $10,76 \%$ para $8,67 \%$, entre 1991 e 2000, apesar do aumento do número absoluto de índios. Pode-se imaginar que uma das causas seja a proliferação dos garimpos nessa região. O Pará e o Amapá também diminuíram essa proporção na população total do estado. Com exceção de Tocantins e Mato Grosso, além dos cinco anteriormente mencionados, em 1991, nos demais estados, a população indígena não chegava nem a $0,50 \%$ da total. $E$ foi nessas Unidades da Federação que ela apresentou o maior crescimento.

O crescimento da população indígena nos estados foi muito grande, o que em parte pode ser devido à forma de coletar os dados de cada censo e aos problemas já citados. O maior crescimento aconteceu em Sergipe, seguido por Piauí, Rio Grande do Norte, Minas Gerais, Goiás, Espírito Santo e Distrito Federal, todos apresentando um incremento anual superior a $20 \%$. Outros 11 estados registraram taxas entre $10 \%$ e $20 \%$. Para o Brasil, o crescimento relativo da população indígena foi de $150 \%$, enquanto para a população brasileira total correspondeu a $15,70 \%$.

Os crescimentos geométricos anuais da população total foram significativamente mais elevados nos estados da Região Norte, sendo o maior no Amapá (5,72\%), seguido por Roraima (4,54\%). No Amazonas e no Acre, as taxas superaram $3 \%$ e em outros sete estados da Região Norte e Centro Oeste e Sergipe foram maiores do que $2 \%$. Os estados das Regiões Nordeste (exceto Sergipe), Sudeste e Sul apresentaram as menores taxas de crescimento no período.

Observa-se que, entre os estados de maior crescimento da população total ou seja, os da Amazônia e Centro Oeste, excetuando-se Rondônia -, Goiás e Distrito Federal foram os que apresentaram as menores taxas de crescimento da população indígena. E inversamente, nos estados onde a população indígena mais cresceu, as populações totais cresceram menos, em geral pouco inferior a $1 \%$ ao ano.

Resumindo as considerações apresentadas, pode-se dizer que os dados sobre o número e o crescimento das populações indígenas no Brasil eram restritos às informações pontuais de antropólogos, pesquisadores, indigenistas e, mais tarde, de organismos como o Cedi (Centro Ecumênico de Documentação e Informação), o Cimi (Conselho Indigenista Missionário) e a própria Funai. De alguns anos para cá, especialmente a partir da década de 90 , observa-se a presença de inúmeras entidades e associações indígenas que vêm fazendo levantamentos parciais, preocupadas em conhecer o número de seus membros para inclusive poderem planejar suas ações.

Em termos de Brasil, conforme salientado, somente a partir do censo de 1991 foi aberta uma categoria classificatória destacando o índio, embora dentro da variável cor e raça, iniciando assim um processo de contagem. Esperamos que o aprimoramento da metodologia de coleta e da contagem possa vir a retratar de forma mais realística e adequada o número de etnias e de índios, e do seu crescimento, nas suas comunidades ou fora delas.

Os acontecimentos e situações citados, quebrando uma tradição de leis que vem desde 1500 protegendo e em seguida desprotegendo os povos indígenas, ${ }^{9} \mathrm{com}$ certeza só puderam ocorrer por estarmos vivendo em uma nova era relativa aos direitos, chamada Estado Democrático de Direito. Esse novo modelo, em tese preocupado com a dignidade, a liberdade e a segurança das pessoas, privilegia questões como o diálogo e o multipluralismo. Quem sabe melhor sorte estará destinada aos grupos indígenas neste país, pois, como já dizia na década de 30 Armando de Salles Oliveira, "o preço da liberdade é a eterna vigilância". E a Constituição Federal de 1988 dá fundamento jurídico constitucional à liberdade dos índios, mas, para torná-la realidade e conservá-la, a luta desses povos terá que ser sempre atenta e contínua.

${ }^{9}$ Vide, especialmente, Miranda e Bandeira (1992) e Oliveira Sobrinho (1992). 


\section{Referências bibliográficas}

ALBERT, B. Associações indígenas e desenvolvimento sustentável na Amazônia brasileira. In: ISA - Instituto Socioambiental. Povos indígenas no Brasil 1996/2000. São Paulo, 2001, p. 197-207.

AZEVEDO, M. M. Demografia dos povos indígenas do Alto Rio Negro. Revista Brasileira de Estudos de População, Campinas, Abep, 11(2): 235-244, jul./dez. 1994.

AZEVEDO, M. M.; FONSECA, G. Os índios e o censo demográfico de 1991. Boletim da ABA, no 29, p. 15-30, 1으 semestre de 1998.

BASTOS, R. J. de M. Sobre a noção de tutela dos povos e indivíduos indígenas pela União. In: SANTOS, S. C. dos et al. (Orgs.). $O$ índio perante o Direito: ensaios. Florianópolis: Ed. UFSC, 1982.

BEVILÁCQUA, C. Código Civil dos Estados Unidos do Brasil - Comentado. 2ª ed. Rio de Janeiro: Livraria Francisco Alves, 1921.

CASTRO, E. V. de. Índios, leis e políticas. In: SANTOS, S. C. dos et al. (Orgs.). O índio perante o Direito: ensaios. Florianópolis: Ed. UFSC, 1982.

FOLHA DE S.PAULO. População indígena cresce 3,5\% ao ano, 24 de março de 2001, A9, dados do ISA e IBGE.

FRANCHETTO, B. O que se sabe sobre as línguas indígenas no Brasil. In: ISA - Instituto Socioambiental. Povos indígenas no Brasil 1996-2000. São Paulo, 2001, p. 84-87.

ISA - Instituto Socioambiental. Povos indígenas no Brasil 1996-2000. São Paulo, 2001.

JUNQUEIRA, C. S. de A.; PAIVA, E. La legislación brasileña y las poblaciones indígenas en Brasil. In: STAVENHAGEN, R. Derecho indígena y derechos humanos en América Latina. México: Instituto Interamericano de Derechos Humanos/El Colégio de México, 1988, p. 243-269.

JUNQUEIRA, C. S. de A. Entrevista a José Corrêa Leite. Em Tempo, TD, abr./maio/ jun. 2000.
MAIA, L. M. (Org.). Legislação indigenista. Brasília: Subsecretaria de Edições Técnicas do Senado Federal, 1993.

MIRANDA, M. T. da C.; BANDEIRA, A. Memorial acerca da antiga e moderna legislação indígena. In: SOUZA FILHO, C. F. $M$. de. Textos clássicos sobre o direito e os povos indígenas. Curitiba: Juruá/NDI, 1992, p. 29-58.

OLIVEIRA SOBRINHO. Os silvícolas brasileiros e a legislação pátria - $O$ decreto legislativo no 5.484, de 1928. In: SOUZA FILHO, C. F. M. de. Textos clássicos sobre o direito e os povos indígenas. Curitiba: Juruá/NDI, 1992, p. 93-124. (Publicado originalmente na Revista Pandectas Brasileiras, v. $\underline{6}, 1 \underline{0}$ semestre 1929).

OLIVEIRA, J. P. de. Contexto e horizonte ideológico; reflexões sobre o Estatuto do Índio. In: SANTOS, S. C. dos et al. (Orgs.). Sociedades indígenas e o Direito - uma questão de direitos humanos - ensaios. Florianópolis: Ed. UFSC/CNPq, 1985, p. 17-30.

PAGLIARO, H. A revolução demográfica dos povos indígenas do Brasil: a experiência dos kaiabi do Parque Indígena do Xingu - Mato Grosso - 1970-1999. Tese de doutorado. São Paulo, Faculdade de Saúde Pública/USP, 2002.

PAPADÓPOLI, M. El nuevo enfoque internacional en matéria de derechos de los pueblos indígenas. Guatemala: IDIES - Universidad Rafael Landívar, 1995 (Série Jurídica).

PENNA, T. C. de F. Por que demografia indígena brasileira? In: ENCONTRO NACIONAL DA ASSOCIAÇÃO BRASILEIRA DE ESTUDOS POPULACIONAIS, IV. Anais... Abep, v. 3, 1984 , p. $1.571-1.578$

PUSSUELO, S. Visão renovada. Brasil Indígena, Brasília, Órgão informativo do Ministério da Justiça, ano 1, no 1, dezembro 1993.

RIBEIRO, B. G. Quantos seriam os índios das Américas? Ciência Hoje, ano 1, no 6 , p. 55-60, maio/junho 1983. 
SOUSA FILHO, C. F. M. de. Tutela aos índios: proteção ou opressão? In: SANTILLI, J. (Coord.). Os direitos indígenas e a Cons- tituição. Porto Alegre: Sergio Fabris/NDI, 1993.

Recebido para publicação em 24/07/2008. Aceito para publicação em 14/11/2008. 